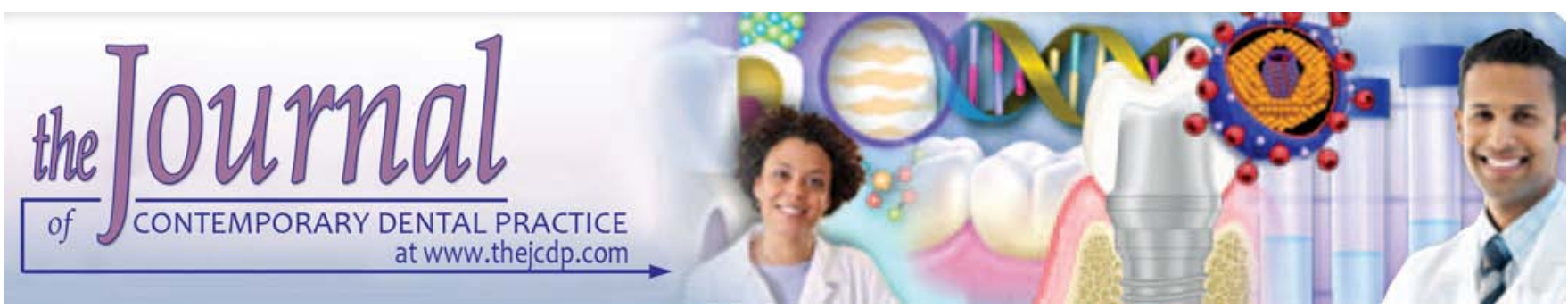

\title{
Lichenoid Features and Fibrosis: Coexistence in Quid-induced Oral Lesions
}

\author{
${ }^{1}$ Sarita Yanduri, ${ }^{2}$ Veerendra B Kumar, ${ }^{3} \mathrm{~S}$ Suma, ${ }^{4} \mathrm{MG}$ Madhura
}

\section{ABSTRACT}

Background: Oral submucous fibrosis (OSF) and quid associated oral lichenoid lesions (QOLL) are caused because of areca nut chewing and both show very characteristic histological changes. The present study aims to determine the histopathological presence of lichenoid features in cases of OSF as well as to determine the presence of fibrosis in cases of QOLL.

Materials and methods: The study involved the retrospective analysis of hematoxylin and eosin stained slides of OSF $(n=50)$ and QOLL $(n=16)$.

Results: Seven cases of OSF revealed histopathological features of lichenoid reaction and four cases of QOLL revealed the presence of fibrosis in the underlying connective tissue.

Conclusion: This study put forths a new finding that is, the presence of concomitant disease processes seen in the same patient at a histological level. It thus, stresses the need to evaluate all cases of OSF and QOLL for additional features which may be induced by areca nut chewing.

Keywords: Areca nut, Oral lichenoid lesions, Oral submucous fibrosis, Quid.

How to cite this article: Yanduri S, Kumar VB, Suma S, Madhura MG. Lichenoid Features and Fibrosis: Coexistence in Quid-induced Oral Lesions. J Contemp Dent Pract 2015;16(5):389-393.

\section{Source of support: Nil}

Conflict of interest: None

${ }^{1-4}$ Department of Oral and Maxillofacial Pathology, DA Pandu Memorial RV Dental College, Bengaluru, Karnataka, India

Corresponding Author: Sarita Yanduri, Reader, Department of Oral and Maxillofacial Pathology, DA Pandu Memorial RV Dental College, CA 37, 24th Main, JP Nagar, 1st Phase Bengaluru 560078, Karnataka, India, Phone: +91-9886147555 e-mail: sarita_yan@yahoo.co.in

\section{INTRODUCTION}

Oral submucous fibrosis (OSF) is a chronic debilitating, potentially malignant disorder caused mainly due to areca nut chewing. ${ }^{1}$ Clinically, there is loss of elasticity of the mucosa leading to blanching and fibrous band formation. ${ }^{2}$ Histopathologically, it is characterized by an inflammatory reaction leading to progressive accumulation of dense collagen fibers in the underlying lamina propria and submucosa, concomitant with epithelial atrophy. ${ }^{3,4}$

It is recognized that the prolonged contact of betel nut/areca nut/tobacco quid with the mucosa of patients with these habits may lead to the development of a type of contact oral lichenoid lesion, which may be referred to as quid associated oral lichenoid lesion (QOLL). ${ }^{2,5}$ Clinically, these lesions appear as white, linear, wavy parallel nonelevated streaks, which may radiate from a central erythematous area. ${ }^{5}$ Histologically, a subepithelial band of inflammatory infiltrate along with liquefactive degeneration of the basal cells is seen. 6,7

Both OSF and QOLL are immunologically mediated disorders with the common etiological factor being areca nut chewing. Thus, there is a possibility that both lesions may occur together in the same patients. ${ }^{8,9}$ Isaac et al on studying 35 cases of OSF reported a new finding, that of the presence of lichenoid features in patients with OSF, though there was no evidence of clinical QOLL. ${ }^{4}$

Based on this, the present study aims to search for similar findings in its institutional OSF cases as well as to go a step forward by also looking for histopathological evidence of fibrosis in patients with clinical evidence of only QOLL.

\section{MATERIALS AND METHODS}

This was a retrospective study involving the retrieval of hematoxylin and eosin stained slides from the archives 
of the department of oral and maxillofacial pathology from the year 2008 to 2014.

The study groups comprised of histologically diagnosed cases of OSF $(n=50)$ and QOLL $(n=16)$. Cases of OSF/QOLL with evidence of dysplasia or squamous cell carcinoma were excluded from the study.

The slides were reviewed for the following:

- Presence or absence of lichenoid features in OSF cases: Lichenoid features included the presence of an inflammatory band close to the epithelium and liquefactive degeneration of the basal cell layer. Additional features like the presence of saw tooth reteridge formation, colloid bodies, reduplication of basement membrane and melanin incontinence were also searched for. The grading of OSF was also done. ${ }^{1}$

- Presence or absence of OSF features in OLL cases: Oral submucous fibrosis features included fibrosis of the connective tissue along with features of the lichenoid reaction.

Review of the slides was done in a blinded manner. Details regarding the age, gender, type of habit, duration and frequency of habit along with the clinical diagnosis were tabulated after reviewing the slides.

Statistical analysis: Chi-square test, Spearman and Pearson correlation test were employed.

\section{RESULTS}

\section{OSF Cases}

Majority of patients were in the age range of 21 to 30 years with $78 \%$ of the cases being male. The predominant habit was gutkha chewing $(48 \%)$ with the duration of habit being between 1 and 5 years. Fifty percent of cases were moderately advanced on histopathological grading. A positive correlation $(\mathrm{r}=0.536)$ was obtained between the duration and the frequency of habit $(\mathrm{p}=0.001)$. Statistically significant results $(p=0.007)$ were obtained while correlating the histopathological grade and type of habit with the moderately advanced and advanced cases being most commonly associated with gutkha chewing.

\section{Lichenoid Features in Cases of OSF}

A total of seven out of 50 cases of OSF (14\%) were found to have an associated lichenoid reaction histopathologically (Tables 1 and 2). Three of these 7 patients were above 50 years and the rest below 50 years. Gender distribution included 4 males and 3 females. Five patients had a habit of gutkha chewing and two of areca nut. The mean duration of habit was 12 years with frequency being 7 times per day. All were histologically graded as having moderately advanced OSF except one which was found to be in the early stage. Out of these seven cases with lichenoid reaction, three were found to have an associated white lesion which was clinically diagnosed as leukoplakia. The other four cases did not show evidence of any associated lesion. All cases showed lichenoid features like basal cell degeneration and a subepithelial band of inflammatory cells (Fig. 1A). The band was found to be dense in some cases and diffuse and perivascular in others. Lymphocytes were the predominant cells with neutrophils and plasma cells also being seen. Saw tooth reteridge formation was seen in majority of the cases while the rest showed atrophic epithelium (Fig. 1B). Melanin incontinence, colloid bodies and reduplication of basement membrane were also evident.

Due to less number of cases reported in this category, the relevant statistical analysis could not be applied.

\section{QOLL Cases}

Majority of the patients (31\%) were in the age group of 21 to 30 years, with a predominant male population $(69 \%)$ being affected. Gutkha was the main habit (50\%) and the predominant duration of habit was between 1 and 5 years. The most common site was buccal mucosa.

\section{OSF Features in Cases of QOLL}

A total of four cases out of 16 cases of QOLL (25\%) were found to exhibit features of OSF in the form of fibrosis of the connective tissue (Tables 3 and 4). One patient was above 50 years and the remaining three were below 50 years. All patients were male and none showed clinical evidence of fibrosis. Borderline significant results $(p=0.05)$

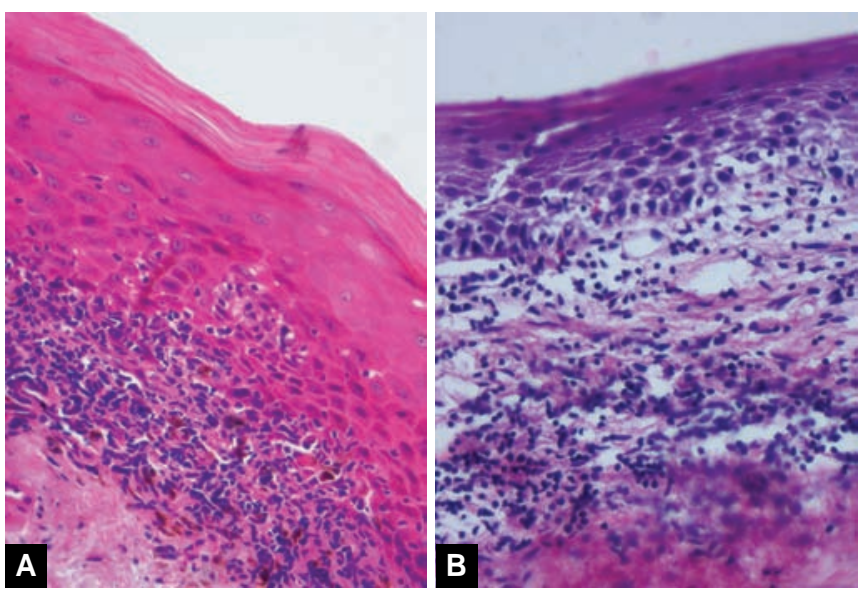

Figs $1 A$ and $B$ : Lichenoid reaction seen in clinically and histologically diagnosed cases of OSF. (A) Saw tooth reteridges, basal cell degeneration, a dense inflammatory band are seen subepithelially. Fibrosis of the underlying connective tissue is evident and (B) Lichenoid features seen similar to $A$ but with an atrophic epithelium without saw tooth reteridges (Hematoxylin and Eosin stained sections, 20x) 
Lichenoid Features and Fibrosis: Coexistence in Quid-induced Oral Lesions

Table 1: Clinical details of cases of OSF with lichenoid features seen histopathologically

\begin{tabular}{lllllll}
\hline Sl. no. & Age (years) & Sex & Habit & Duration (years) & Frequency (times/day) & Any associated lesion \\
\hline Case 1 & 70 & M & Gutkha & 30 & 10 & Leukoplakia \\
Case 2 & 26 & M & Gutkha & 5 & 5 & Leukoplakia \\
Case 3 & 68 & F & Gutkha & 10 & 10 & Leukoplakia \\
Case 4 & 65 & F & Areca nut & 25 & 15 & Nil \\
Case 5 & 23 & F & Areca nut & 5 & 5 & Nil \\
Case 6 & 42 & M & Gutkha & 5 & 5 & Nil \\
Case 7 & 38 & M & Gutkha & 10 & 4 & NII \\
\hline
\end{tabular}

Table 2: Details of histopathological lichenoid features seen in OSF cases

\begin{tabular}{|c|c|c|c|c|c|c|c|c|}
\hline SI. no. & $\begin{array}{l}\text { Histological grade of } \\
\text { OSF }\end{array}$ & $\begin{array}{l}\text { Subepithelial } \\
\text { band of } \\
\text { inflammatory } \\
\text { cells }\end{array}$ & $\begin{array}{l}\text { Type of } \\
\text { inflammatory } \\
\text { cells }\end{array}$ & $\begin{array}{l}\text { Saw tooth } \\
\text { reteridges }\end{array}$ & $\begin{array}{l}\text { Basal cell } \\
\text { degeneration }\end{array}$ & $\begin{array}{l}\text { Melanin } \\
\text { incontinence }\end{array}$ & $\begin{array}{l}\text { Colloid } \\
\text { bodies }\end{array}$ & $\begin{array}{l}\text { Reduplication } \\
\text { of basement } \\
\text { membrane }\end{array}$ \\
\hline Case 1 & Moderately advanced & Dense band & Lymphocytes & $\mathrm{P}$ & $P$ & $\mathrm{P}$ & $P$ & $A$ \\
\hline Case 2 & Early & Diffuse band & $\begin{array}{l}\text { Lymphocytes, } \\
\text { plasma cells }\end{array}$ & $\mathrm{P}$ & $\mathrm{P}$ & $\mathrm{P}$ & $P$ & $\mathrm{P}$ \\
\hline Case 3 & Moderately advanced & Diffuse band & Lymphocytes & $\mathrm{P}$ & $P$ & A & $A$ & $A$ \\
\hline Case 4 & Moderately advanced & Dense band & $\begin{array}{l}\text { Lymphocytes, } \\
\text { eosinophils }\end{array}$ & A & $P$ & $A$ & A & $A$ \\
\hline Case 5 & Moderately advanced & $\begin{array}{l}\text { Dense but } \\
\text { localised }\end{array}$ & $\begin{array}{l}\text { Lymphocytes, } \\
\text { neutrophils }\end{array}$ & $A$ & $P$ & $A$ & $A$ & $A$ \\
\hline Case 6 & Moderately advanced & Diffuse & Lymphocytes & $\mathrm{P}$ & $\mathrm{P}$ & A & $A$ & $A$ \\
\hline Case 7 & Moderately advanced & $\begin{array}{l}\text { Diffuse and } \\
\text { perivascular }\end{array}$ & Lymphocytes & $\mathrm{P}$ & $\mathrm{P}$ & $\mathrm{P}$ & $A$ & $A$ \\
\hline
\end{tabular}

P: Present; A: Absent

Table 3: Clinical details of cases of QOLL with fibrosis

\begin{tabular}{lllllll}
\hline Sl. no. & Age (years) & Sex & Habit & Duration (years) & Frequency (times/day) & Any associated lesion \\
\hline Case 1 & 38 & M & Areca nut & 5 & 5 & Nil \\
Case 2 & 29 & M & Gutkha & 3 & 2 & Nil \\
Case 3 & 65 & M & Gutkha & 15 & 5 & Nil \\
Case 4 & 27 & M & Gutkha & 5 & 5 & Nil \\
\hline
\end{tabular}

Table 4: Histopathological details of cases of QOLL with fibrosis

\begin{tabular}{|c|c|c|c|c|c|c|c|c|}
\hline SI. no. & $\begin{array}{l}\text { Subepithelial } \\
\text { band of } \\
\text { inflammatory } \\
\text { cells }\end{array}$ & $\begin{array}{l}\text { Type of } \\
\text { inflammatory } \\
\text { cells }\end{array}$ & $\begin{array}{l}\text { Basal cell } \\
\text { degeneration }\end{array}$ & $\begin{array}{l}\text { Saw tooth } \\
\text { reteridges }\end{array}$ & $\begin{array}{l}\text { Melanin } \\
\text { incontinence }\end{array}$ & $\begin{array}{l}\text { Colloid } \\
\text { bodies }\end{array}$ & $\begin{array}{l}\text { Reduplication } \\
\text { of basement } \\
\text { membrane }\end{array}$ & $\begin{array}{l}\text { Location of } \\
\text { fibrosis in } \\
\text { connective } \\
\text { tissue }\end{array}$ \\
\hline Case 1 & Diffuse & Lymphocytes & $P$ & $\mathrm{P}$ & $A$ & $A$ & $P$ & Deeper \\
\hline Case 2 & Diffuse & Lymphocytes & $\mathrm{P}$ & $\mathrm{P}$ & A & $A$ & A & Subepithelial \\
\hline Case 3 & $\begin{array}{l}\text { Diffuse and } \\
\text { perivascular }\end{array}$ & Lymphocytes & $\mathrm{P}$ & $\mathrm{P}$ & $\mathrm{P}$ & A & A & Subepithelial \\
\hline Case 4 & Diffuse & Lymphocytes & $\mathrm{P}$ & $\mathrm{P}$ & $\mathrm{P}$ & A & A & Subepithelial \\
\hline
\end{tabular}

P: Present; A: Absent

were seen with respect to the presence of fibrosis and type of habit with gutkha being predominant. A positive correlation (rho $=0.816$ ) was also seen between the presence of fibrosis and frequency of habit. Histopathologically, all showed a diffuse band of inflammatory cells with mainly lymphocytes being seen. Basal cell degeneration was also evident in all cases. Fibrosis was seen subepithelially in three cases while in the fourth case fibrosis was in the deeper connective tissue (Figs 2A and B).

\section{DISCUSSION}

Betel nut chewing/areca nut chewing is a common practice in the Indian population. A workshop held in Malaysia in 1996 defined a quid as 'a substance or a mixture of substances, placed in the mouth or chewed and remaining in contact with the mucosa, usually containing one or both of the two basic ingredients, tobacco or areca nut in raw or any manufactured form.' The three types of contents of a quid are areca nut only, tobacco 


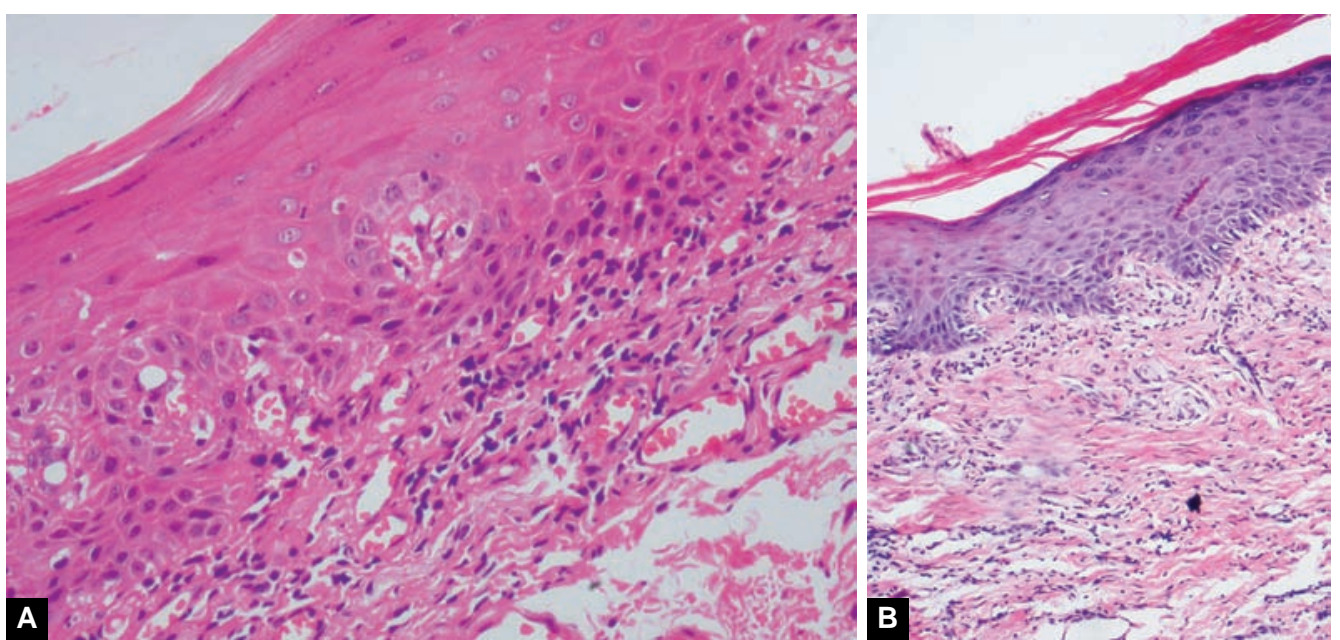

Figs 2A and B: Fibrosis seen in clinically and histologically diagnosed cases of quid associated lichenoid lesion. (A) Fibrosis seen subepithelially and (B) Fibrosis seen in the deeper connective tissue (Hematoxylin and Eosin stained sections, 20x)

only or a mixture of both. Another type of quid is called betel quid, which refers to any quid that is wrapped in a betel leaf. Other ingredients that can be used in the quid are lime paste, mishri (burned tobacco), niswar (tobacco snuff), and nass (a stronger form of niswar). ${ }^{10}$ Gutkha, a commercially available mixture of tobacco and areca nut is another form of habit commonly used in the Indian population as seen in the present study where majority of the patients reported with this habit. ${ }^{11}$

The constant contact of these chemical substances with the mucosa may lead to a number of associated lesions like chewer's mucosa, leukoplakia, oral submucous fibrosis and quid induced lichenoid lesions. ${ }^{2}$

Daftary was the first person to report a case of oral lichen planus like lesion in Indian betel nut chewers during an epidemiologic study of oral cancer and precancer in the Indian population in Kerala. ${ }^{12}$ Zain et $\mathrm{al}^{2}$ renamed this lesion as 'betel quid lichenoid lesion'. In the present study, the term 'quid associated oral lichenoid lesions' has been used since all quid may not be wrapped in betel leaf.

Unfortunately, though areca nut chewing, in various forms, is such a common habit in India, literature on the existence of these lesions is very scanty. Isaac in a study of 35 cases of OSF reported a new finding of lichenoid features seen histopathologically in $45.7 \%$ of their cases. They did not report the presence of any clinical lichenoid lesions. ${ }^{4}$

Keeping this in mind, a retrospective study was carried out to search for this same feature in 50 cases of OSF. However, the study revealed that only $14 \%$ of cases showed histopathological evidence of lichenoid features like a subepithelial inflammatory band, basal cell degeneration and saw tooth reteridges along with the characteristic features of OSF. On retrieving the clinical information, it was noticed that three out of seven cases had clinical evidence of leukoplakia along with
OSF. However, on a histopathological level, features of lichenoid reaction were seen. Nonetheless, like in Isaac's study, the remaining four cases did not show any clinical evidence of a lesion other than OSF.

The second part of the study involved the search for features of fibrosis in cases which had been both clinically and histopathologically diagnosed as having lichenoid lesions. It was seen that four cases did show fibrosis either subepithelially or in the deeper connective tissue though, there were no clinical features of OSF in these patients.

Despite the number of cases reported in this study being low, based upon the present results, it can be speculated that though clinical evidence of the disease may not be present, it is possible that at a histological level lichenoid changes or fibrosis may occur. These findings may be the initial changes in the disease process, and thus such a study may provide an interesting insight, as taking a biopsy in a patient without clinical evidence of disease is unethical. It would also be interesting to find out whether these individuals with OSF and no clinical lichenoid features except at a histological level would develop lichenoid lesions at a later date. Similarly, the patients with clinical evidence of lichenoid lesions and with fibrosis seen histologically may also develop OSF later. This, however, is subject to the patient continuing the habit. Nevertheless more studies are required to validate these findings.

The full etiology and pathogenesis of both OSF and QOLL remains poorly understood but both are chronic inflammatory diseases. The persistent mechanical and chemical stress to the oral mucosa caused by the areca nut chewing remains a key feature in the development of both lesions in the same patient. Li et al demonstrated that CXCL9, an inflammatory chemokine was upregulated in patients with concomitant OSF and QOLL, and thus suggested that they may share a common pathogenic process 
wherein the CXCL9 was responsible for the recruitment of lymphocytes. ${ }^{8}$

Betel quid substitutes contain both carcinogens and genotoxic agents which have a role in multistage progression of oral cancer. Smokeless tobacco contains nitrosonornicotine and 4-(methylnitrosamino)-1-(3pyridyl)-1-butanone; areca nut contains arecoline and 3-(methylnitrosamino) propionitrile, while lime provides reactive oxygen radicals, each of which has a role in oral carcinogenesis. ${ }^{10}$ Oral submucous fibrosis is a known potentially malignant disorder with a malignant transformation rate of 3 to $19 \% .^{5}$ There is growing evidence that oral lichenoid lesions also have a malignant potential, though the premalignant potential of betel quid associated lichenoid lesions is unknown. ${ }^{13-15}$ Thus, there is a possibility that patients with concomitant lesions may be more prone to the development of oral cancer. Li et al suggested that the cancerization of OSF mucosa might come from the malignant change of lichenoid lesion in OSF. ${ }^{8}$

Therefore, any lesions associated with areca nut or betel quid use must be adequately diagnosed and managed aggressively to decrease the risk of malignant transformation. ${ }^{10}$ Quid associated oral lichenoid lesions are known to regress after stoppage of habit, though it may not be the case for OSF patients. ${ }^{5}$ Nevertheless, discontinuation of the habit must be advised as this may improve the prognosis of the quid induced lesions.

\section{CONCLUSION}

In summary, simultaneous manifestation of OSF and QOLL in the same patients is known to occur. However, this study shows that sometimes when there is no clinical evidence of concomitant lesions, there is a possibility of changes being seen at the histopathological level indicating early evidence of the disease process. This is a new finding, and thus may help to throw light on the mechanism of these two diseases.

\section{REFERENCES}

1. Pindborg JJ, Sirsat SM. Oral submucous fibrosis. Oral Surg Oral Med Oral Pathol 1966;22(6):764-779.
2. Zain RB, Ikeda N, Gupta PC, Warnakulasuriya S, van Wyk CW, Shrestha P, Axéll T. Oral mucosal lesions associated with betel quid, areca nut and tobacco chewing habits: consensus from a workshop held in Kuala Lumpur, Malaysia, November 25-27, 1996. J Oral Pathol Med 1999;28(1):1-4.

3. Rajalalitha P, Vali S. Molecular pathogenesis of oral submucous fibrosis-a collagen metabolic disorder. J Oral Pathol Med 2005;34(6):321-328.

4. Isaac U, Issac JS, Ahmed KN. Histopathologic features of oral submucous fibrosis: a study of 35 biopsy specimens. Oral Surg Oral Med Oral Pathol Oral Radiol Endod 2008;106(4):556-560.

5. Reichart PA, Warnakulasuriya S. Oral lichenoid contact lesions induced by areca nut and betel quid chewing: a mini review. J Investig Clin Dent 2012;3(3):163-166.

6. Acay RR, Felizzola CR, de Araújo N, de Sousa SO. Evaluation of proliferative potential in oral lichen planus and oral lichenoid lesions using immunohistochemical expression of p53 and Ki67. Oral Oncol 2006;42:475-480.

7. Ismail SB, Kumar SKS, Zain RB. Oral lichen planus and lichenoid reactions: etiopathogenesis, diagnosis, management and malignant transformation. J Oral Sci 2007;49(2):89-106.

8. Li N, Hu Q, Jiang C, Guo F, Munnee K, Jian X, Hu Y, Tang Z. Cys-X-Cys ligand 9 might be an immunological factor in the pathogenesis of oral submucous fibrosis and its concomitant oral lichenoid lesion. Clin Oral Investig 2013;17(4):1251-1258.

9. Angadi PV, Rekha KP. Oral submucous fibrosis: a clinicopathologic review of 205 cases in Indians. Oral Maxillofac Surg 2011;15(1):15-19.

10. Stoopler ET, Parisi E, Sollecito TP. Betel quid-induced oral lichen planus: a case report. Cutis 2003;71(4):307-311.

11. Patil PB, Bathi R, Chaudhari S. Prevalence of oral mucosal lesions in dental patients with tobacco smoking, chewing, and mixed habits: a cross-sectional study in South India. J Family Community Med 2013;20(2):130-135.

12. Daftary DK, Bhonsle RB, Pindborg JJ, Murtui PR, Mehta FS. An oral lichen planus like lesion in Indian betel-tobacco chewers. Scand J Dent Res 1980;88:244-249.

13. van der Meij EH, Mast $H$, van der Waal I. The possible premalignant character of oral lichen planus and oral lichenoid lesions: a prospective five-year follow-up study of 192 patients. Oral Oncol 2007;43(8):742-748.

14. Auluck A, Hislop G, Poh C, Zhang L, Rosin MP. Areca nut and betel quid chewing among South Asian immigrants to Western countries and its implications for oral cancer screening. Rural Remote Health 2009;9(2):1118.

15. PatilS, Rao RS, Sanketh DS, Sarode SC, Sarode GS. A universal diagnostic criteria for oral lichen planus: an exigency! Int J Contemp Dent Med Rev 2014, (2014). Article ID 041214 doi: 10.15713/ins.ijcdmr.15. 